\title{
Peptide-Based Probes for Cancer Imaging
}

Receptors for regulatory peptides are overexpressed in a variety of human cancers. They represent the molecular basis for in vivo imaging with radiolabeled peptide probes. Somatostatin-derived tracers, designed to image the sst $_{2}$-overexpressing neuroendocrine tumors, have enjoyed almost 2 decades of successful development and extensive clinical applications. More recent developments include second- and third-generation somatostatin analogs, with a broader receptor subtype profile or with antagonistic properties. Emerging tracers for other peptide receptors, including cholecystokinin/gastrin and GLP-1 analogs for neuroendocrine tumors, bombesin and neuropeptide-Y analogs for prostate or breast cancers, or Arg-Gly-Asp peptides for neoangiogenesis labeling, are also in current development. Application fields include both SPECT/CT and PET/CT.

Key Words: PET/CT; peptide-based probes; SPECT/CT; cholecystokinin/gastrin; somatostatin analogs

J Nucl Med 2008; 49:1735-1738

DOI: 10.2967/jnumed.108.053041

Specific targeting of tumors through selective molecules, either for diagnostic or for therapeutic reasons, is increasingly considered a promising strategy in oncology, compared with earlier, less-specific approaches. Regulatory peptides represent such a class of molecules developed for specific cancer targeting; they have had a relatively short history of about 2 decades ( 1 ) but are now given increasing interest, as they often compare advantageously to immunotargeting with antibodies. Indeed, whereas antibodies have been confronted with problems linked to poor diffusion and target accessibility, peptides have several advantages such as small size, implying good tissue diffusion and target accessibility, but also no antigenicity, easy synthesis, and adequate radiolabeling. Chemically, a peptide is any combination of amino acids linked together with peptide bonds. Among the vast number of potentially interesting molecules, regulatory peptides-for example, naturally occurring peptides with a size ranging from a few amino acids to a few dozen amino acids - have gained particular interest for cancer imaging in the last few years. These peptides physiologically play a modulatory role in the human body in regions as varied as the brain; gastrointestinal tract; and endocrine, vascular, or lymphoid systems. They mediate their functions through high-affinity, specific, usually G-protein-coupled receptors. The presence of physiologic peptide receptors in the human body may appear as a poor prerequisite for specific and selective tumor imaging. However, compared with their relatively low density in physiologic organs, many of these peptide

Received Aug. 20, 2008; revision accepted Sep. 9, 2008.

For correspondence or reprints contact: Jean Claude Reubi, Division of Cell Biology and Experimental Cancer Research, Institute of Pathology, University of Berne, P.O. Box 62, Murtenstrasse 31, CH-3010 Berne, Switzerland.

E-mail: reubi@pathology.unibe.ch

COPYRIGHT @ 2008 by the Society of Nuclear Medicine, Inc. receptors have been shown to be massively overexpressed in numerous cancers $(1,2)$. This is the key reason why these regulatory peptide receptors have become so interesting and important in cancer imaging in recent times. The first and currently best example of targeted peptide receptors is represented by the somatostatin receptors, discovered to be overexpressed in a majority of neuroendocrine tumors as early as 1984 (1). Such tumors include gastrointestinal and bronchial neuroendocrine tumors, pituitary adenomas, paragangliomas, pheochromocytomas, and neuroblastomas. The significance of somatostatin receptors in molecular imaging of these cancers is prominent and is paradigmatic in this field (3). This article discusses the significance of somatostatin receptors in molecular imaging together with the value of other peptides for cancer targeting.

\section{PRINCIPLE OF PEPTIDE-BASED CANCER IMAGING}

In somatostatin-based cancer imaging (Fig. 1), a stable somatostatin analog linked to a chelator that can bind radioactive metals such as ${ }^{111} \mathrm{In},{ }^{99 \mathrm{~m}} \mathrm{Tc}$, or ${ }^{68} \mathrm{Ga}$ is injected intravenously into the circulation of a patient with a potential neuroendocrine tumor. The radiotracer will distribute in the body. If the patient has a tumor expressing somatostatin receptors in large amounts, the tracer will selectively bind to these somatostatin receptors and will actively be taken up by the cells through a process called receptor-ligand internalization. The internalization will ultimately lead to an accumulation of radioactivity in the tumor, compared with the rest of the organs; it will be amenable to detection through $\gamma$-camera scanning and PET (Fig. 1). Normally, rapid and specific uptake is observed in the tumor, and concomitant labeling of kidney and bladder is also found, as a consequence of the predominant urinary excretion pathway of most radioligands. The sensitivity of this type of cancer imaging is excellent, with tumors of a few millimeters in diameter often being identified; several large studies have proposed somatostatin receptor scintigraphy as the method of choice for the detection of some of the gastroenteropancreatic tumors.

\section{PEPTIDE PROBES}

\section{Somatostatin Analogs for Neuroendocrine Tumors}

The radioactive somatostatin-based probes that are presently available in the clinic are primarily based on octreotide, a synthetic and metabolically stable somatostatin analog. In the late 1980s, the existence of this potent and stable analog as a nonradioactive drug markedly reduced the time needed for developing adequate targeting radioligands. The first commercially available agent was ${ }^{111} \mathrm{In}-$ diethylenetriaminepentaacetic acid (DTPA) ${ }^{0}$-octreotide (Table 1), originally designed for scintigraphy. The drawbacks of this radiopeptide are its moderate binding affinity to $\mathrm{sst}_{2}$ and that DTPA is not a suitable chelator for commercially available $\beta$-emitters such as ${ }^{90} \mathrm{Y}$ and ${ }^{177} \mathrm{Lu}$. For these radiometals, it is better to use the macrocyclic chelator 1,4,7,10-tetraazacyclododecane-1,4,7,10-tetraacetic acid (DOTA), which forms thermodynamically and kinetically stable metal 
FIGURE 1. (A) Principle of peptide receptor targeting of cancer. Radioactive peptide $(P)$ is injected intravenously into patient and distributes through circulation. If patient has tumor expressing corresponding peptide receptor $(\mathrm{P}-\mathrm{R})$ in its cancer cells, radiopeptide will bind to receptor and be internalized with receptor. Accumulation of radioactivity will permit $\gamma$-camera imaging and PET of tumor. (B) Somatostatin receptor scan of gastro-

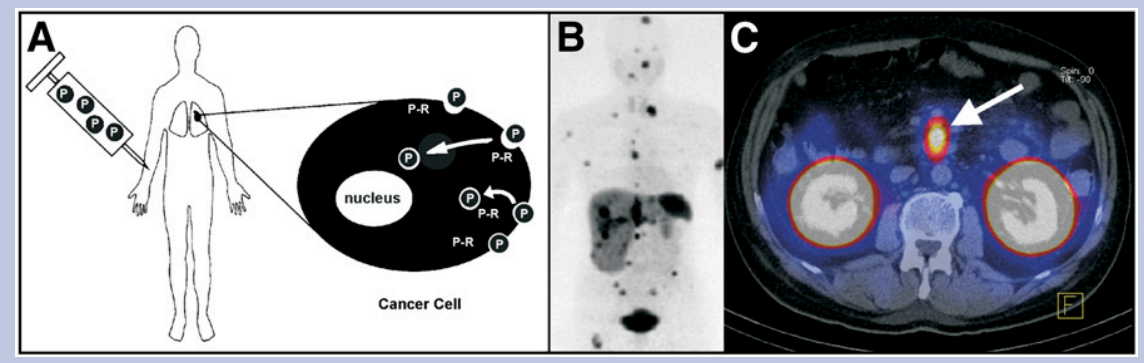
enteropancreatic tumor with ${ }^{68} \mathrm{Ga}-\mathrm{DOTA}-\mathrm{NOC}$ as radioligand. (Reprinted with permission of (25).) (C) GLP-1 receptor scan of insulinoma using $\left[\mathrm{Lys}^{40}\left(\mathrm{Ahx}^{-111} \mathrm{In}-\mathrm{DOTA}\right) \mathrm{NH}_{2}\right]$-exendin-4 as radioligand. Arrow identifies insulinoma. (Reprinted with permission of (13).)

complexes. The most frequently used DOTA-coupled, somatostatinbased radiopeptides are $\left[\right.$ DOTA $\left.^{0}, \mathrm{Tyr}^{3}\right]$-octreotide (DOTATOC) and $\left[\right.$ DOTA $^{0}, \mathrm{Tyr}^{3}, \mathrm{Thr}^{8}$ ]-octreotide (DOTATATE) (3). A recent strategy has been to couple octreotide or octreotate derivatives to carbohydrates to improve tracer pharmacokinetics, and ${ }^{18} \mathrm{~F}$-labeled tracers suitable for routine clinical imaging have been developed on that principle (4). 6Hydrazinopyridine-3-carboxylic acid-TATE (HYNIC-TATE), HYNICTOC, and $\mathrm{N}_{4}$-TATE were designed for high-specific-activity labeling with ${ }^{99 \mathrm{~m}} \mathrm{Tc}$ and have proven to be additional compounds in clinical development based on the octreotide backbone and suitable for diagnostic imaging (3).

Although several of the sst $_{2}$-preferring analogs mentioned here are currently used in the clinic, further development of somatostatin-based radioligands, with a broader receptor subtype affinity profile, has been initiated. Such compounds may not only extend the range of targeted cancer candidates but also increase the net tumor uptake, given the presence of several receptor subtypes on the same tumor cell (1). Several new compounds have been developed that show high affinity to $\mathrm{sst}_{2}, \mathrm{sst}_{3}$, and $\mathrm{sst}_{5}$. These new compounds were modified at position 3 of the octapeptide, the best of them containing the unnatural amino acids 1-naphtyl-alanine (DOTA-NOC) and benzothienyl-alanine (DOTA-BOC) (5). A ${ }^{68} \mathrm{Ga}$-DOTA-NOC scan is shown in Figure 1. As further extension of this approach, attempts have also been made to develop pansomatostatin radioligands with high-affinity binding for all receptor subtypes. The first such peptide, KE 108, was modified by coupling DOTA to the $\mathrm{N}$ terminus (In-KE-88) (6). Although it was still able to bind with high affinity to all 5 somatostatin receptor subtypes, its expected imaging capabilities were not fulfilled, because ${ }^{111} \mathrm{In}-\mathrm{KE}-88$

TABLE 1

Peptide Receptors, Corresponding Cancer Indications, and Peptide Probes

\begin{tabular}{|c|c|c|c|c|}
\hline Peptide & Receptor & Cancer indication & Peptide probe & Reference \\
\hline \multirow[t]{10}{*}{ Somatostatin } & sst $_{2}$ & Neuroendocrine tumors* & DTPA-octreotide & \\
\hline & & & DOTA-TOC & \\
\hline & & & DOTA-TATE & 3 (review) \\
\hline & & & Hynic-TATE, HYNIC-TOC & \\
\hline & & & $\mathrm{N}_{4}$-TATE & \\
\hline & & & ${ }^{18} \mathrm{~F}$-carbohydrated-TATE & 4 \\
\hline & $\mathrm{sst}_{2} / \mathrm{sst}_{3} / \mathrm{sst}_{5}$ & Neuroendocrine tumors ${ }^{\star}$ & DOTA-NOC/DOTA-BOC & 5 \\
\hline & $\mathrm{sst}_{1} / \mathrm{sst}_{2} / \mathrm{sst}_{3} / \mathrm{sst}_{4} / \mathrm{sst}_{5}$ & Neuroendocrine tumors & DOTA-pan-somatostatin (KE-88) & 6 \\
\hline & sst $_{2}$ & Neuroendocrine tumors & DOTA-sst ${ }_{2}$-antag (antagonist) & 8 \\
\hline & $\mathrm{sst}_{3}$ & Neuroendocrine tumors & DOTA-ODN-8-sst ${ }_{3}$ (antagonist) & 8 \\
\hline \multirow[t]{4}{*}{ CCK, gastrin } & $\mathrm{CCK}_{2}$ & Medullary thyroid cancer* & DTPA-minigastrin & \\
\hline & & & DTPA-CCK (nonsulfated) & 10 (review) \\
\hline & & & Demogastrin & \\
\hline & & & DOTA-minigastrin 11 and 9 & 14 \\
\hline \multirow[t]{4}{*}{ Bombesin } & GRP-R & Prostate cancer*; breast cancer ${ }^{\star}$ & RP 527 & 12 \\
\hline & & & AMBA & 15 \\
\hline & & & DOTA/DTPA-panbombesin & 16 \\
\hline & & & Demobesin 1 (antagonist) & 17 \\
\hline \multirow[t]{2}{*}{ GLP-1 } & GLP-1 R & Insulinomas* & {$\left[\right.$ Lys $\left.^{40}(\mathrm{Ahx}-\mathrm{DTPA}) \mathrm{NH}_{2}\right]$-exendin-4 } & \\
\hline & & & {$\left[\right.$ Lys $\left.^{40}(\mathrm{Ahx}-\mathrm{DOTA}) \mathrm{NH}_{2}\right]$-exendin- 4} & 13 \\
\hline NPY & $Y_{1}$ & Breast cancer; sarcomas & {$\left[\right.$ Lys(DOTA) ${ }^{4}$, Phe $^{7}$, Pro $\left.^{34}\right]$ NPY } & 20 \\
\hline RGD peptides & $\alpha_{\mathrm{v}} \beta_{3}$-integrin & Various ${ }^{\star}$ & Various & 21 (review) \\
\hline $\begin{array}{l}\text { *Proof of prin } \\
\text { TATE }=\left[\mathrm{Tyr}^{3}\right.\end{array}$ & vivo in patients av & & & \\
\hline
\end{tabular}


had a disappointingly low in vitro internalization and in vivo uptake in $\mathrm{sst}_{2}$ tumors, compared with $\mathrm{sst}_{3}$ tumors (6). An explanation for the low internalization and uptake is not yet available.

Up to now, there has been a consensus to develop compounds with good radioligand internalization properties, as high in vivo accumulation of radioligands in the tumors appeared to be required for optimal visualization in vivo. It is well known from molecular-pharmacologic investigations that efficient internalization is usually provided by agonists (7). However, we have recently shown that high-affinity somatostatin receptor antagonists that poorly internalize in tumor cells can, in terms of in vivo uptake in animal tumors, perform as well as or even better than the corresponding agonists, which massively internalize (8). This unexpected phenomenon was found both for $\mathrm{sst}_{2}$ - and for $\mathrm{sst}_{3}$-selective somatostatin analogs, suggesting that this observation may be valid for more than just 1 particular G-proteincoupled receptor, as these radioligands bind to distinct receptors (8). Figure 2 illustrates the in vitro and in vivo properties of such an $\mathrm{sst}_{3}$ antagonist. A clinical trial with radiolabeled DOTA-linked $\mathrm{sst}_{2}$ antagonists is presently under way and will hopefully confirm the animal data. More potent $\mathrm{sst}_{2}$ antagonists aimed at that same purpose are in development (9).

\section{Other Regulatory Peptides for a Variety of Tumors}

Peptide-based cancer imaging is not limited to somatostatin receptors and neuroendocrine tumors. It was convincingly shown in the last 2 decades that many other cancer types can indeed overexpress regulatory peptide receptors (2). This is the case, in particular, for cholecystokinin-2
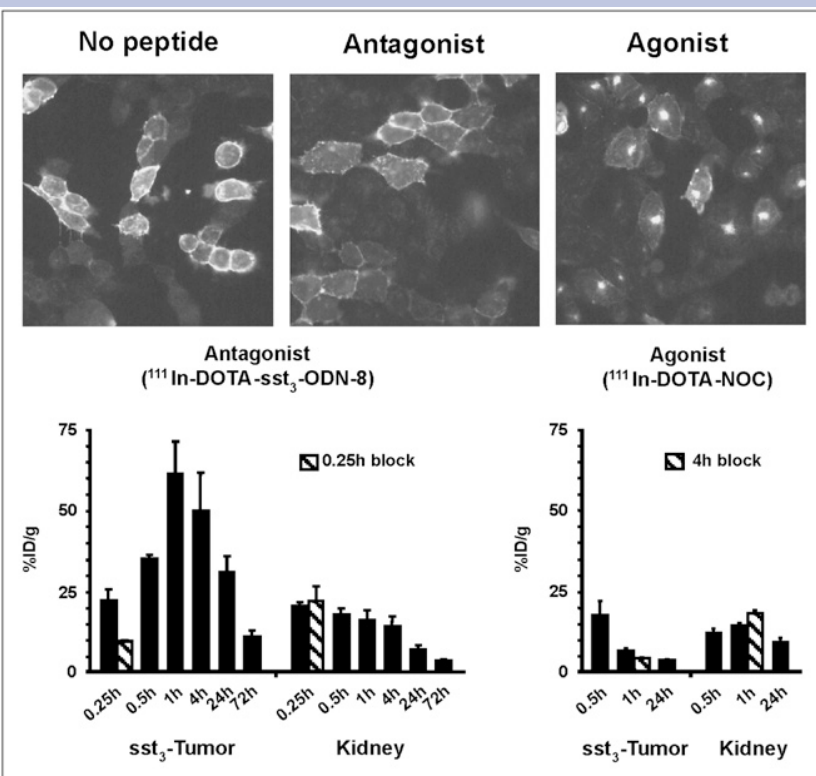

FIGURE 2. $\mathrm{sst}_{3}$ antagonists are preferable to agonists for tumor targeting. In vitro $\mathrm{sst}_{3}$ receptor immunofluorescence shows that antagonist DOTA-sst $3-\mathrm{ODN}-8$ does not trigger measurable $\mathrm{sst}_{3}$ internalization, as opposed to massive $\mathrm{sst}_{3}$ internalization by agonist DOTA-NOC (top). Absence of peptide (no peptide) as control shows $\mathrm{sst}_{3}$ localized at membrane. In vivo biodistribution of ${ }^{111} \mathrm{In}$-labeled $\mathrm{sst}_{3}$ antagonist and agonist over time in transplanted sst $_{3}$-expressing tumors and in kidneys of same animals (bottom). \%ID/g = percentage injected dose per gram of tissue; block = uptake blocking experiment in presence of excess cold peptide.
(CCK2) receptors in medullary thyroid cancers; gastrin-releasing peptide (GRP) receptors in prostate and breast cancers; neurotensin receptors in pancreatic cancers; GLP-1 receptors in insulinomas; and neuropeptide-Y (NPY) receptors in breast tumors, sarcomas, and glioblastomas. Proof of principle has been well provided that CCK2 receptors $(10,11)$, GRP receptors (12), and GLP-1 receptors (13) can be targeted in specific cancers. A successful proof of concept does not necessarily mean that the tracer used in such studies will be the tracer of choice that can be used for routine clinical investigations. Research is still needed to find optimal peptide probes characterized by high binding affinity, good stability, high tumor-to-kidney ratios, and suitable radiophysical properties. Currently available probes for selected peptide receptors are discussed in the next sections and in Table 1.

CCK/Gastrin. The CCK2 ligands used for the first proof of concept were DTPA-linked nonsulfated CCK analogs or a DTPA-d-Glu chelator-modified minigastrin (10). Added value of gastrin receptor scintigraphy with such compounds, compared with somatostatin receptor scintigraphy, could be documented in selected neuroendocrine tumors (11). However, because of inappropriate tumor-to-kidney ratio or occasional low sensitivity, these compounds are not going to be developed further. New gastrin-derived ligands, however, in which glutamic acid residues have been reduced from the minigastrin derivative, retain excellent receptor affinity with a much lower kidney uptake (14). These truncated radiopeptides show an improved binding affinity to the CCK2 receptor and retain high tumor uptake in the rat AR42J tumor model but show a reduced kidney uptake, reflected by a more than 10 -fold improvement in the tumor-tokidney ratio (14).

Bombesin. Several bombesin-based ligands with high affinity for GRP receptors have been developed. An early report used a ${ }^{99 \mathrm{~m}} \mathrm{Tc}-$ based ligand, RP 527, an $\mathrm{N}_{3} \mathrm{~S}$ chelator coupled to bombesin (7-14) via a gly-5-aminovaleric acid spacer that can be labeled with high specific activity and radiochemical yield. RP 527 can successfully identify primary breast and prostate cancers and their metastases (12). A more recently developed analog is ${ }^{177} \mathrm{Lu}-\mathrm{AMBA}$, which may be used for diagnostic and therapeutic applications (15). Another bombesin agonist with a novel receptor profile, a panbombesin analog, is characterized by high affinity to all 3 bombesin receptors with possibly broader indications (16). An interesting compound is ${ }^{99 \mathrm{~m} T c-d e m o b e s i n, ~ a ~}$ tetraamine-derivatized [d-Phe ${ }^{6}$, Leu-NHEt ${ }^{13}$, desMet ${ }^{14}$ ] bombesin $(6-$ 14) that turns out to be a full competitive antagonist (17). ${ }^{99 \mathrm{~m}} \mathrm{Tc}-$ demobesin does not internalize significantly into PC-3 tumor cells but is able, nevertheless, to label in vivo GRP-R-expressing PC-3 tumors more intensely and for a longer time than the best available GRP-R agonists (17). This extends the paradigm shift on tumor imaging observed earlier with somatostatin antagonists to GRP-R.

$G L P-1$. GLP-1, an intestinal hormone that stimulates insulin secretion through receptors expressed on islet cells, has been found to have receptors that are massively overexpressed in virtually all insulinomas (18). Therefore, radiolabeled versions of GLP-1 and its metabolically more stable congeners, exendin- 3 and -4 , have been developed and studied in mouse models. ${ }^{111}$ In was coupled to these peptides via DTPA complexation, or more recently, via DOTA complexation. The latter radioligand was found to remarkably label and localize human insulinomas that were not detected by conventional imaging and permitted a precise and complete surgical tumor resection (13). Such an example is shown in Figure 1.

$N P Y$. Numerous attractive indications for NPY radioligand targeting have been formulated recently on the basis of in vitro receptor autoradiography data in human cancers. Next to $\mathrm{Y}_{1}$-expressing breast cancers, $\mathrm{Y}_{1}$-expressing sarcomas were also identified (19). The group of Beck-Sickinger has been particularly active in developing $\mathrm{Y}_{1^{-}}$ 
and $\mathrm{Y}_{2}$-preferring radiotracers. Their most recent article reports on the synthesis and characterization of a large number of NPY analogs (20). A potent and well-characterized radiotracer is $\left[\mathrm{Lys}\left({ }^{111}{ }^{I n} \text {-DOTA }\right)^{4}, \mathrm{Phe}^{7}\right.$,$\mathrm{Pro}^{34}$ ]-NPY. Unfortunately, in animal biodistribution studies this compound had an extremely high kidney and low tumor uptake, making it an unlikely candidate for further development. None of the available radiolabeled NPY analogs has yet been tested in humans.

ARG-GLY-ASP (RGD) Peptides. These peptides do not belong to the regulatory peptide family, but they are important as they can target neoangiogenic vessels through their integrin receptors (21). Of particular interest is the $\alpha_{\nu} \beta_{3}$ receptor, an integrin receptor and attractive target for therapeutic intervention and diagnostic imaging. Mono- and multivalent RGD-based compounds were labeled with a variety of radionuclides showing promising preclinical results. The most promising tracer, ${ }^{18} \mathrm{~F}$ galacto-RGD, was studied in patients with melanoma, sarcoma, and breast cancer. The conjugation of the carbohydrate necessitates a rapid blood clearance primarily via the kidneys. Standardized uptake values range from 1.2 to 9.0, with good tumor-to-blood and tumor-to-muscle ratios. Because of the tedious, relatively low-yield synthesis of the tracer, new PET tracers based on metallic positron emitters are under development. These tracers offer new strategies for noninvasive monitoring of the tumor microenvironment and appear to allow specific imaging of $\alpha_{\nu} \beta_{3}$ expression in patients.

\section{Which Isotope to Choose?}

The widely used somatostatin-based peptides were labeled with a variety of radionuclides for SPECT $\left({ }^{111} \mathrm{In},{ }^{99 \mathrm{~m}} \mathrm{Tc}\right.$, and $\left.{ }^{67} \mathrm{Ga}\right)$ and for PET $\left({ }^{18} \mathrm{~F},{ }^{68} \mathrm{Ga}\right.$, and $\left.{ }^{64} \mathrm{Cu}\right) . \gamma$-Emitters appear to have undergone a kind of renaissance due to the availability of sophisticated SPECT/CT. ${ }^{111} \mathrm{In}$ is an attractive radionuclide because it often can be used as a surrogate of the $\beta$-emitters ${ }^{90} \mathrm{Y}$ and ${ }^{177} \mathrm{Lu}$. ${ }^{99 \mathrm{~m}} \mathrm{Tc}$, still one of the workhorses, has its obvious advantages; powerful kit formulations are in use for the HYNICTOC and $\mathrm{N}_{4}$-TATE conjugates. The application of ${ }^{68} \mathrm{Ga}$-labeled peptides has attracted much attention because of the availability of a cost-effective generator and the available chemistry (22). Mainly, ${ }^{68} \mathrm{Ga}$-DOTA-TOC, ${ }^{68} \mathrm{Ga}$-DOTA-TATE, and ${ }^{68} \mathrm{Ga}$-DOTA-NOC are being studied in clinical trials. In addition, ${ }^{68} \mathrm{Ga}$-based bombesin derivatives were studied in gastrointestinal stromal tumors (23). The 68-min half-life of this radionuclide is suitable for the pharmacokinetics of most peptides. Another widely used, attractive metallic positron emitter is ${ }^{64} \mathrm{Cu}$. It can be produced in large scale at high specific activity with a medical cyclotron. Although its half-life of $12.7 \mathrm{~h}$ may be superior to that of ${ }^{68} \mathrm{Ga}$ for many applications, its decay characteristics $\left(19 \% \beta^{+} ; 39 \% \beta^{-}\right)$may not be ideal for patient dosimetric reasons. Nevertheless, somatostatin-based ${ }^{64} \mathrm{Cu}$-labeled conjugates show promising preclinical properties (24). This also applies for RGD- and bombesin-based radiopeptides; as already indicated, ${ }^{18} \mathrm{~F}$-labeled peptides were developed and those based on somatostatin and RGD were successfully studied in patients (4).

\section{CONCLUSION}

Considering the success of somatostatin receptor targeting as a niche indication in neuroendocrine tumors, we can extrapolate to the large number of novel candidate peptides and expect a boom in molecular imaging when peptide receptors overexpressed in key tumors such as breast, prostate, or pancreas carcinomas can finally be targeted. This will largely depend on the development of adequate probes, which continues to be a considerable challenge.

Jean Claude Reubi University of Berne Berne, Switzerland
Helmut R. Maecke

University Hospital

Basel, Switzerland

\section{REFERENCES}

1. Reubi JC. Peptide receptors as molecular targets for cancer diagnosis and therapy. Endocr Rev. 2003;24:389-427.

2. Reubi JC, Macke HR, Krenning EP. Candidates for peptide receptor radiotherapy today and in the future. $J$ Nucl Med. 2005;46(suppl 1):67S-75S.

3. Rufini V, Calcagni ML, Baum RP. Imaging of neuroendocrine tumors. Semin Nucl Med. 2006;36:228-247.

4. Schottelius M, Poethko T, Herz M, et al. First ${ }^{18} \mathrm{~F}$-labeled tracer suitable for routine clinical imaging of sst receptor-expressing tumors using positron emission tomography. Clin Cancer Res. 2004;10:3593-3606.

5. Ginj M, Chen J, Walter MA, Eltschinger V, Reubi JC, Maecke HR. Preclinical evaluation of new and highly potent analogues of octreotide for predictive imaging and targeted radiotherapy. Clin Cancer Res. 2005;11:1136-1145.

6. Ginj M, Zhang H, Eisenwiener KP, et al. New pansomatostatin ligands and their chelated versions: affinity profile, agonist activity, internalization, and tumor targeting. Clin Cancer Res. 2008;14:2019-2027.

7. Cescato R, Schulz S, Waser B, et al. Internalization of sst2, sst3 and sst5 receptors: effects of somatostatin agonists and antagonists. J Nucl Med. 2006;47:502511.

8. Ginj M, Zhang H, Waser B, et al. Radiolabeled somatostatin receptor antagonists are preferable to agonists for in vivo peptide receptor targeting of tumors. Proc Natl Acad Sci USA. 2006;103:16436-16441.

9. Cescato R, Erchegyi J, Waser B, et al. Design and in vitro characterization of highly sst2-selective somatostatin antagonists suitable for radiotargeting. $\mathrm{J} \mathrm{Med}$ Chem. 2008;51:4030-4037.

10. Reubi JC. Targeting CCK receptors in human cancers. Curr Top Med Chem. 2007; 7:1239-1242.

11. Gotthardt M, Behe MP, Grass J, et al. Added value of gastrin receptor scintigraphy in comparison to somatostatin receptor scintigraphy in patients with carcinoids and other neuroendocrine tumours. Endocr Relat Cancer. 2006;13: 1203-1211.

12. Van de Wiele $\mathrm{C}$, Phonteyne $\mathrm{P}$, Pauwels $\mathrm{P}$, et al. Gastrin-releasing peptide receptor imaging in human breast carcinoma versus immunohistochemistry. $\mathrm{J} \mathrm{Nucl} \mathrm{Med}$. 2008;49:260-264.

13. Wild D, Mäcke H, Christ E, Gloor B, Reubi JC. Glucagon-like peptide 1-receptor scans to localize occult insulinomas. N Engl J Med. 2008;359:766-768.

14. Good S, Walter MA, Waser B, et al. Macrocyclic chelator-coupled gastrin-based radiopharmaceuticals for targeting of gastrin receptor-expressing tumours. Eur $J$ Nucl Med Mol Imaging. May 29, 2008 [E-pub ahead of print].

15. Lantry LE, Cappelletti E, Maddalena ME, et al. ${ }^{177} \mathrm{Lu}-\mathrm{AMBA}$ : synthesis and characterization of a selective ${ }^{177} \mathrm{Lu}$-labeled GRP receptor agonist for systemic radiotherapy of prostate cancer. $J$ Nucl Med. 2006;47:1144-1152.

16. Zhang H, Chen J, Waldherr C, et al. Synthesis and evaluation of bombesin derivatives on the basis of pan-bombesin peptides labeled with indium-111, lutetium-177, and yttrium-90 for targeting bombesin receptor-expressing tumors. Cancer Res. 2004;64:6707-6715.

17. Cescato R, Maina T, Nock B, et al. Bombesin receptor antagonists may be preferable to agonists for tumor targeting. J Nucl Med. 2008;49:318-326.

18. Reubi JC, Waser B. Concomitant expression of several peptide receptors in neuroendocrine tumors as molecular basis for in vivo multireceptor tumor targeting. Eur J Nucl Med. 2003;30:781-793.

19. Körner M, Waser B, Reubi JC. High expression of neuropeptide y1 receptors in Ewing sarcoma tumors. Clin Canc Res. 2008;14:5043-5049.

20. Zwanziger D, Khan IU, Neundorf I, et al. Novel chemically modified analogues of neuropeptide Y for tumor targeting. Bioconjug Chem. 2008;19:1430-1438.

21. Haubner R. Alpha v beta 3-integrin imaging: a new approach to characterise angiogenesis? Eur J Nucl Med Mol Imaging. 2006;33(suppl 1):S54-S63.

22. Maecke HR, Hofmann M, Haberkorn U. ${ }^{68} \mathrm{Ga}$-labeled peptides in tumor imaging. J Nucl Med. 2005;46(suppl 1):172S-178S.

23. Dimitrakopoulou-Strauss A, Hohenberger P, Haberkorn U, Macke HR, Eisenhut M, Strauss LG. ${ }^{68} \mathrm{Ga}$-labeled bombesin studies in patients with gastrointestinal stromal tumors: comparison with ${ }^{18}$ F-FDG. J Nucl Med. 2007;48: 1245-1250.

24. Wadas TJ, Wong EH, Weisman GR, Anderson CJ. Copper chelation chemistry and its role in copper radiopharmaceuticals. Curr Pharm Des. 2007;13:3-16.

25. Wild D, Macke HR, Waser B, et al. ${ }^{68}$ Ga-DOTANOC: a first compound for PET imaging with high affinity for somatostatin receptor subtypes 2 and 5. Eur J Nucl Med Mol Imaging. 2005;32:724. 